\title{
Supplementation effects of pomegranate by-products on oxidative status, metabolic profile, and performance in transition dairy cows
}

\author{
M. Safari, E. Ghasemi, ${ }^{1}$ M. Alikhani, and S. Ansari-Mahyari \\ Department of Animal Science, College of Agriculture, Isfahan University of Technology, Isfahan 84156-83111, I. R. Iran
}

\begin{abstract}
Recent studies demonstrated a high antioxidant capacity for pomegranate components due to their rich bioactive compounds, such as conjugated fatty acids and phenolics. The objective of the present study was, therefore, to assess whether pomegranate seed or pomegranate seed pulp (peel + seed) supplementation could be effective to improve antioxidant status, and hence metabolic profile and performance in periparturient dairy cows. After a 1-wk pretreatment period, Holstein cows (primiparous $\mathrm{n}=12$, multiparous $\mathrm{n}=$ 18) were assigned to 3 dietary treatments from $25 \mathrm{~d}$ before expected calving through $25 \mathrm{~d}$ postcalving. The dietary treatments included (1) control (CON); (2) diet supplemented with pomegranate seeds (PS; $400 \mathrm{~g} / \mathrm{cow}$ per day); and (3) diet supplemented with pomegranate seed pulp (PSP; $400 \mathrm{~g}$ of seeds/cow per day $+1200 \mathrm{~g}$ of peels/cow per day). Compared with CON, supplementation with either PS or PSP had no effects on dry matter intake, rumen fermentation, and plasma concentrations of cholesterol, total protein, globulin, and aspartate amino transferase, but enhanced plasma total antioxidant activity, and lowered triacylglycerol, free fatty acids (FFA), and $\beta$-hydroxybutyrate at both pre- and postpartum periods. Plasma concentration of glucose, albumin, malondialdehyde (MDA) and blood superoxide dismutase (SOD) activity were not affected by dietary treatments at prepartum, whereas SOD activity increased and glucose, albumin, MDA, and FFAto-albumin ratio decreased by feeding both by-products at postpartum period. In contrast to PS, supplementing PSP resulted in a greater decrease in plasma glucose and triacylglycerol concentration and higher increase in SOD activity. Energy- and fat-corrected milk yields were higher in cows fed PSP diet compared with those fed CON or PS diets, but content of milk fat, protein, and lactose were similar across the dietary treatments.
\end{abstract}

Received January 27, 2018.

Accepted June 12, 2018.

${ }^{1}$ Corresponding author: ghasemi@cc.iut.ac.ir
These findings indicated that dietary pomegranate byproducts supplementation, in particular PSP, could improve antioxidant status, which was associated with a decline in lipid oxidation (FFA and $\beta$-hydroxybutyrate) and peroxidation (MDA) and an enhancement in glucose utilization as well as fat-corrected milk yield.

Key words: pomegranate peel, pomegranate seed, oxidative stress, transition cows

\section{INTRODUCTION}

During transition period, various changes in endocrine and metabolic status are required to accommodate parturition and lactogenesis in dairy cows. The increase in metabolic demand during the periparturient period is accompanied by increased rates of reactive oxygen species (ROS) production (Gaál et al., 2006). When an overload of ROS (e.g., $\mathrm{O}_{2}^{-}, \mathrm{OH}^{*}, \mathrm{H}_{2} \mathrm{O}_{2}$ ) cannot be neutralized by antioxidant defenses, a condition referred to as oxidative stress ensues (Pham-Huy et al., 2008). Growing evidence has implicated oxidative stress as an inducer of tissue injury in several pathological conditions in transition dairy cows (Brzezinska-Slebodzinska et al., 1994; Gaál et al., 2006; Abuelo et al., 2016). Increased lipid peroxidation, decreased plasma antioxidant concentrations, and low antioxidative enzyme activity have been established as typical findings in the blood samples of transition dairy cows (Bernabucci et al., 2005). Hence, supplementation of external source of antioxidants, such as $\alpha$-tocopherol, $\beta$-carotene, or micronutrients (e.g., Mn, Se, Zn) that increase the ability of antioxidant enzymes, are applied to prevent damages caused by ROS, in an attempt to decrease the incidence of postpartum diseases (Brzezinska-Slebodzinska et al., 1994; Yasui et al., 2014).

Pomegranate as a nutraceutical source has received considerable attentions, as it is a rich source of natural antioxidant compounds (Tzulker et al., 2007). About $50 \%$ of the fruit weight corresponds to the peel, and the edible part of pomegranate fruit consists of $40 \%$ arils and $10 \%$ seeds (Aviram et al., 2000). Previous studies (Singh et al., 2002; Tzulker et al., 2007) indicated greater antioxidant capacity of the pomegranate by- 
products compared with the juice. Pomegranate peel is a rich source of water-soluble polyphenols, including mainly hydrolyzable tannins (e.g., punicalagins and punicalins) as well as phenolic acids, flavonoids, and proanthocyanidins (Tzulker et al., 2007; Jurenka, 2008). These compounds are known to scavenge free radicals as well as having antimicrobial, antiatherosclerotic, anti-inflammatory, anticancer, immunomodulatory, and numerous health-promoting properties (Singh et al., 2002; Jurenka, 2008; Shabtay et al., 2008). Several investigations have demonstrated the beneficial effects of pomegranate-derived products on abundance of ruminal methanogenic activity (Jami et al., 2012), feed intake and weight gain (Shabtay et al., 2008), meat total phenolics and oxidative stability (Kotsampasi et al., 2014), and milk yield and milk antioxidant activity and essential fatty acids (FA) profile (Modarasi et al., 2011; Shabtay et al., 2012). The pomegranate seed, the other by-product of pomegranate juice processing, mainly contains conjugated FA, punicic acid (cis-9,trans-11,cis-13 octadecatrienoic acid) as well as phytoestrogens, sterols, $\gamma$-tocopherol, and hydroxyl benzoic acids (Fadavi et al., 2006; Liu et al., 2009). The presence of these components in pomegranate seed or conjugated FA have also been shown to possess antioxidant and anti-inflammatory activity in vitro (Singh et al., 2002) and in lactating dairy cows (Hanschke et al., 2016).

The rich functional compounds, such as phenolics and conjugated FA, in pomegranate peel and seed make these by-products an attractive component to improve antioxidant status, thereby improving health. Whereas sufficient information exists on biological effects of pomegranate components as a nutraceutical source in vitro, in humans, and in some cases in the ruminant diet, limited data are available to assess the potential antioxidant and metabolic effects of different pomegranate components on dairy cattle, particularly during the transition period. Therefore, we aimed to evaluate the effects of feeding pomegranate seed pulp and pomegranate seed on oxidative status, metabolic profile, and performance of transition dairy cows.

\section{METARIALS AND METHODS}

\section{Pomegranate By-Products}

Pomegranate by-products (seeds and peels) were provided after juice production by a commercial juiceextracting factory (Doneh Co., Shahreza, Isfahan, Iran). Fresh pomegranate peels and seeds were separately air-dried in the sun for $7 \mathrm{~d}$. Before feeding, the final DM was 88.0 and $81.3 \%$ for pomegranate seed and pomegranate peel, respectively. A stationary for- age chopper was used to chop pomegranate peels, and pomegranate seeds were ground by a hammer mill using a $3-\mathrm{mm}$ screen before inclusion in the diets.

\section{Animals and Diets}

The experiment was conducted at the farm facilities of the Lavark Research Station (Isfahan University of Technology, Isfahan, Iran) from April to August 2016. Thirty dry Holstein cows (18 multiparous with BW = $727 \pm 22.3 \mathrm{~kg}$, and 12 primiparous with $\mathrm{BW}=608$ $\pm 15.9 \mathrm{~kg}$ ) were selected and housed in individual barn stalls $(4 \times 4 \mathrm{~m})$ from $32 \mathrm{~d}$ prepartum and fed the same prepartum basal diet for $7 \mathrm{~d}$. Holstein cows were blocked by parity, and randomly allocated to 1 of 3 diets containing (1) no pomegranate by-products (CON); (2) pomegranate seeds (PS); or (3) pomegranate seed pulp (PSP) containing a blend of pomegranate peels and seeds. Pomegranate seeds was supplemented at a rate of $350 \mathrm{~g}$ of DM per cow, which corresponded to 2.9 and $2.2 \%$ dietary DM for prepartum (predicted $\mathrm{DMI}=12.0 \mathrm{~kg} / \mathrm{d}$ ) and postpartum (predicted DMI = $16.0 \mathrm{~kg} / \mathrm{d}$ ) diets, respectively. Pomegranate seed pulp was applied at rates of $1,350 \mathrm{~g}$ of DM per cow (350 g of pomegranate seeds $+1,000 \mathrm{~g}$ of peels DM), which corresponded to 11.2 and $8.4 \%$ dietary DM for prepartum and postpartum diets, respectively. The blend ratio for pomegranate peels and seeds was determined to be 4:1 based on previous reports in whole pomegranate pulp (Aviram et al., 2000). Pomegranate by-products were substituted for beet pulp in the diets as described in Table 1. Diets were formulated to be isocaloric and isonitrogenous and to meet NRC (2001) requirements of close-up or recommended amounts for fresh cows. Cows were fed the experimental dietary treatments from 25 d before the expected calving date to $25 \mathrm{~d}$ postpartum. Water was available at all times and wood shavings were used for bedding. The 3 diets were fed as a TMR once daily $(0930 \mathrm{~h})$ prepartum and twice daily (0930 and $1500 \mathrm{~h}$ ) postpartum, and allowing for 5 to $10 \%$ refusal. After parturition, cows were milked 3 times daily at 0100, 0900, and $1700 \mathrm{~h}$.

\section{Sample Collection and Analysis}

Milk yield of individual cows was recorded during postpartum period. Samples of milk were collected from 3 milkings every other day from 1 to 25 DIM. Samples were stored at $4^{\circ} \mathrm{C}$ with a preservative (sodium azide; $6 \mathrm{mg} / \mathrm{mL}$ ) to determine milk composition (fat, protein, lactose, and TS) using an automated near-infrared spectroscopy analyzer (MilkoScan, 134 BN Foss Electric, Hillerød, Denmark). The yields of $3.5 \%$ FCM $(0.432 \times$ milk yield $+16.23 \times$ fat yield $)$ 
and $\operatorname{ECM}(12.82 \times$ fat yield $+7.13 \times$ protein yield + $0.323 \times$ milk yield) were calculated according to NRC (2001) equations. Cows were weighed weekly and BCS was determined at $\mathrm{d}-25,0$, and 25 postpartum using a 5 -point scale, where $1=$ emaciated and $5=$ obese.

Manual weighing of feeds and refusals were performed daily for individual cows throughout the experiment. The TMR and refusal samples were taken weekly before the morning feeding and frozen at $-20^{\circ} \mathrm{C}$ for later analysis. After thawing, samples were composited, dried at $60^{\circ} \mathrm{C}$ for $48 \mathrm{~h}$ in a forced-air oven, and then ground to pass a 1-mm screen using a Wiley mill (Arthur Thomas Co., Philadelphia, PA). Samples were analyzed for DM (method 930.15; AOAC International, 2000), ash (method 942.05; AOAC International, 2000), $\mathrm{N}$ using the Kjeldahl method (990.03; AOAC Interna- tional, 2000), ether extract (method 2003.05; AOAC International, 2000), and NDF using an ANKOM200 fiber analyzer (ANKOM Technology Corp., Fairport, NY) with heat-stable $\alpha$-amylase.

To measure total phenolic and antioxidant activity in pomegranate by-products and TMR, $4 \mathrm{~g}$ of ground sample was extracted with $80 \mathrm{~mL}$ of aqueous methanol (80:20 vol/vol; dark bottle) in an ultrasonic bath for 30 min and then centrifuged $(10,000 \times g, 10 \mathrm{~min}$, room temperature). Extracts ( $1 \mathrm{~mL}$ ) were diluted with aqueous methanol $80 \%$ (99 mL). Sample extract $(1 \mathrm{~mL})$ was mixed with $4 \mathrm{~mL}$ of $7.5 \% \mathrm{Na}_{2} \mathrm{CO}_{3}$, and $5 \mathrm{~mL}$ of the Folin-Ciocalteu reagent (1:10 diluted) and then centrifuged $(10,000 \times g, 10 \mathrm{~min}$, room temperature). After 30 min, the optical density was measured at $760 \mathrm{~nm}$ using a UV-Photometer (UV-Vis array Spectrophotometer,

Table 1. Ingredients and nutrient composition (DM basis) of prepartum and postpartum diets containing no pomegranate by-products (CON), pomegranate seed (PS), or pomegranate seed pulp (PSP)

\begin{tabular}{|c|c|c|c|c|c|c|}
\hline Item & \multicolumn{3}{|c|}{ Prepartum } & \multicolumn{3}{|c|}{ Postpartum } \\
\hline \multicolumn{7}{|l|}{ Ingredient, $\%$ of $\mathrm{DM}$} \\
\hline Alfalfa hay & 11.0 & 11.0 & 11.0 & 18.8 & 18.8 & 18.8 \\
\hline Wheat straw & 4.0 & 4.0 & 4.0 & - & - & - \\
\hline Beet pulp & 10.8 & 8.42 & - & 8.13 & 6.31 & - \\
\hline Soybean meal & 5.8 & 6.1 & 7.9 & 13.4 & 13.6 & 15.0 \\
\hline Canola meal & 5.0 & 5.0 & 4.2 & 2.0 & 2.1 & 1.5 \\
\hline Fish meal & - & - & - & 0.94 & 0.94 & 0.94 \\
\hline Soybean whole, extruded & 4.2 & 3.3 & 3.3 & 3.8 & 3.1 & 3.1 \\
\hline Fat powder & - & - & - & 0.94 & 0.94 & 0.94 \\
\hline Carbonate calcium & - & - & - & 0.69 & 0.69 & 0.56 \\
\hline Magnesium oxide & - & - & - & 0.31 & 0.31 & 0.31 \\
\hline Pomegranate peel & - & - & 8.33 & - & - & 6.25 \\
\hline \multicolumn{7}{|c|}{ Chemical composition, \% of DM (unless otherwise noted) } \\
\hline $\mathrm{DM}$ & 57.5 & 55.9 & 57.3 & 57.2 & 57.3 & 58.1 \\
\hline $\mathrm{CP}$ & 13.3 & 13.5 & 13.0 & 17.5 & 17.2 & 17.6 \\
\hline NDF & 42.3 & 41.4 & 42.1 & 34.9 & 35.3 & 33.4 \\
\hline Physically effective NDF & 28.0 & 29.0 & 29.0 & 23.0 & 24.0 & 23.0 \\
\hline $\mathrm{NFC}^{3}$ & 34.4 & 34.4 & 35.4 & 37.1 & 36.3 & 37.9 \\
\hline Ether extract & 3.1 & 3.5 & 3.5 & 3.9 & 4.2 & 4.2 \\
\hline $\mathrm{NE}_{\mathrm{L}}, \mathrm{Mcal} / \mathrm{kg}$ of $\mathrm{DM}$ & 1.53 & 1.52 & 1.54 & 1.61 & 1.61 & 1.63 \\
\hline Calcium & 0.48 & 0.46 & 0.53 & 0.81 & 0.81 & 0.80 \\
\hline Phosphorous & 0.35 & 0.36 & 0.36 & 0.37 & 0.38 & 0.39 \\
\hline Total phenolic compounds, $\mathrm{g} / \mathrm{kg}$ & 0.280 & 0.563 & 1.18 & 0.519 & 0.855 & 1.36 \\
\hline \multicolumn{7}{|l|}{ Antioxidant activity } \\
\hline Inhibition of radical activity, $\%$ & 13.51 & 11.98 & 20.85 & 13.30 & 13.94 & 27.92 \\
\hline
\end{tabular}

${ }^{1}$ Contained per kilogram (DM basis) $0.8 \mathrm{~g}$ of iron; $16 \mathrm{~g}$ of zinc; $10 \mathrm{~g}$ of manganese; $4 \mathrm{~g}$ of copper; $0.15 \mathrm{~g}$ of iodine; $0.12 \mathrm{~g}$ of cobalt; and $0.08 \mathrm{~g}$ of selenium.

${ }^{2}$ Contained per kilogram (DM basis) $1,300,000 \mathrm{IU}$ of vitamin $\mathrm{A} ; 360,000 \mathrm{IU}$ of vitamin $\mathrm{D}_{3} ; 12,000 \mathrm{IU}$ of vitamin E.

${ }^{3} \mathrm{NFC}=100-(\% \mathrm{NDF}+\% \mathrm{CP}+\%$ fat $+\%$ ash $)$ based on NRC (2001).

${ }^{4}$ Ascorbic acid equivalent antioxidant capacity. 
Photonix Ar, 2017) with tannic acid as standard (1-100 $\mathrm{mg} / \mathrm{L}$; Bamdad et al., 2006). The antioxidant capacity of the extracts was measured using 1,1-diphenyl2-picryl hydroxyl method. Five milliliters of a $0.1 \mathrm{mM}$ methanolic solution of 1,1-diphenyl-2-picryl hydroxyl was mixed with $0.1 \mathrm{~mL}$ of sample extracts or ascorbic acid $(2-100 \mathrm{mg} / \mathrm{L})$. Control was prepared this way without any extracts. Changes in the absorbance of the samples were read at $517 \mathrm{~nm}$. The percentage inhibition was calculated by the equation (control OD - sample OD)/control OD $\times 100$. Chemical analysis of the feeds were performed in triplicates and means are presented in Table 1.

On d 25 postpartum, ruminal fluid were obtained $4 \mathrm{~h}$ after the morning feeding using a stomach tube attached to an Erlenmeyer flask connected to vacuum pump. After discarding initial sample $(\sim 100 \mathrm{~mL})$, sample was strained through a 4-layers of cheesecloth and $\mathrm{pH}$ was determined immediately using a portable $\mathrm{pH}$ meter (HI 8314 membrane pH meter, Hanna Instruments, Villafranca, Italy). A sample of the filtered ruminal fluid (5 $\mathrm{mL}$ ) was added to $1 \mathrm{~mL}$ of metaphosphoric acid (250 $\mathrm{g} / \mathrm{L}$ ) and retained for short-chain fatty acids (SCFA) determination. Individual SCFA concentrations were measured by GC (CP-9002; Chrompack, Middelburg, the Netherlands) using a silica-fused column (CP-Wax Chrompack Capillary Column; Varian, Palo Alto, CA) with helium as a carrier gas. The initial and final oven temperatures were set at 55 and $195^{\circ} \mathrm{C}$, respectively. Detector and injector temperatures were set at $250^{\circ} \mathrm{C}$. Crotonic acid (1:7, vol/vol) was used as the internal standard.

For all cows, blood samples were collected $4 \mathrm{~h}$ after the morning feeding on $\mathrm{d}-14,1,7,14$, and 21 relative to expected calving. Blood samples were taken from coccygeal vessel using evacuated tubes containing anticoagulant heparin. Plasma samples were separated following centrifugation $(2,000 \times \mathrm{g}, 20 \mathrm{~min}$, room temperature) and stored frozen in plastic micro-tubes at $-20^{\circ} \mathrm{C}$ for later analysis. Samples were analyzed for concentrations of albumin (photometric test using bromocresol green, $546 \mathrm{~nm}$; Catalog number: 101500), total protein (Biuret method, $560 \mathrm{~nm}$; Catalog number: 128500), triacylglycerol (TAG; enzymatic method using glycerol-3-phosphate oxidase-phenol 4 aminoantipyrine peroxidase, $505 \mathrm{~nm}$; Catalog number: 132500), cholesterol (enzymatic method using cholesterol oxidase-phenol 4-aminoantipyrine peroxidase, $546 \mathrm{~nm}$; Catalog number: 110500), glucose (enzymatic method using glucose oxidase-phenol 4-aminoantipyrine peroxidase, $505 \mathrm{~nm}$; Catalog number: 117500), and aspartate aminotransferase (AST; International Federation of Clinical Chemistry and Laboratory Medicine method without pyridoxal phosphate, $340 \mathrm{~nm}$; Catalog num- ber: 118400) using commercial kits (Pars Azmun Co. Ltd., Karaj, Iran). The assay procedures followed the manufacturer's instructions (Pars Azmun Co. Ltd.; http://parsazmun.ir/Products/Index/2022) by an autoanalyzer (BT 1500, Biotecnica SpA, Rome, Italy). Globulin concentration was calculated by subtracting total protein from albumin. Concentrations of BHB ( $\beta$-hydroxybutyrate dehydrogenase method, $340 \mathrm{~nm}$ ), free fatty acids (FFA; RX Monza test), and total antioxidant capacity (TAC; metmyoglobin chromogen method) were measured calorimetrically by commercial kits (Randox Laboratories Ltd., Ardmore, UK) using the same autoanalyzer. Malondialdehyde (MDA) levels were measured based on the reaction of MDA with thiobarbituric acid as described by Zhang et al. (2006), and the absorbance was measured at $532 \mathrm{~nm}$. For determination of superoxide dismutase (SOD) activity, a blood sample was centrifuged for $10 \mathrm{~min}$ at 2,000 $\times \mathrm{g}$ at room temperature and then aspirated off the plasma. Erythrocytes were washed 4 times with $3 \mathrm{~mL}$ of $0.9 \%$ $\mathrm{NaCl}$ solution and centrifuging for $10 \mathrm{~min}$ at 2,000 $\times \mathrm{g}$ (room temperature). After the final wash, erythrocytes were lysed using $2.0 \mathrm{~mL}$ of cold redistilled water and left at $4^{\circ} \mathrm{C}$ for $15 \mathrm{~min}$. The lysate was diluted with 0.01 $\mathrm{mol} / \mathrm{L}$ of phosphate buffer $(\mathrm{pH} 7.0)$. The activity of SOD was measured using xanthine and xanthine oxidase to generate superoxide radicals which react with iodonitrotetrazolium chloride (INT, $505 \mathrm{~nm}$ ) using Randox kit (Catalog number: SD 125; Randox Laboratories) according to the manufacturer's protocol (http://www .tokyofuturestyle.com/pdf/randox_RANSOD.pdf).

\section{Statistical Analysis}

Two cows from the CON treatment and 1 cow from the PS treatment were removed because of displaced abomasum, lameness, and milking problems through the experiment. However, 1 cow was added to treatment 1 to have at least 9 replications. The blood metabolites data were analyzed for $\mathrm{d}-14$ as prepartum data and d 1, 7, and 21 as postpartum. Data were analyzed for a completely randomized block design using the mixed model procedure in SAS (SAS 9.0 for windows, SAS Institute Inc., Cary, NC). Feed intake, BW change, and blood parameter data were analyzed separately for 2 discrete periods as prepartum (d -25 to 0 relative to calving) and postpartum (d 1 to 25 relative to calving) periods. Time was used as repeated measures and the first-order autoregressive variance-covariance matrix structure that provided the best fit according to Schwarz's Bayesian information criterion. Variables with repeated measurements (DMI, BW, milk yield, feed efficiency, and blood parameters) within the same cow were analyzed using the model 
Table 2. Chemical composition, phenolic compounds, and antioxidant activity of pomegranate seed and pomegranate peel

\begin{tabular}{lcc}
\hline Item & $\begin{array}{c}\text { Pomegranate } \\
\text { seed }\end{array}$ & $\begin{array}{c}\text { Pomegranate } \\
\text { peel }\end{array}$ \\
\hline Chemical composition & & 81.3 \\
DM, \% of sun dried & 88.0 & 3.02 \\
CP, \% of DM & 12.6 & 19.7 \\
NDF, \% of DM & 49.6 & 13.1 \\
ADF, \% of DM & 39.0 & 1.94 \\
Ether extract, \% of DM & 12.1 & 3.88 \\
Ash, \% of DM & 2.03 & 68.9 \\
NFC ${ }^{1}$ & 8.33 & 25.5 \\
Phenolics, g/kg & 1.61 & 21.9 \\
Total phenolic compounds & 1.31 & 3.62 \\
Total tannins & 0.11 & 91.6 \\
Condensed tannins & 12.8 & 240.2 \\
Antioxidant activity & 21.1 & \\
Inhibition of radical activity (1,1-diphenyl-2-picryl hydroxyl) $\%$ & & \\
AAEAC, ${ }^{2}$ mg/100 g & &
\end{tabular}

$$
\begin{aligned}
\mathrm{Y}_{\mathrm{ij}(\mathrm{k}) \mathrm{m}}= & \mu+\mathrm{P}_{\mathrm{i}}+\mathrm{T}_{\mathrm{j}}+\mathrm{C}(\mathrm{T})_{\mathrm{jk}}+\mathrm{D}_{\mathrm{l}} \\
& +\mathrm{T} \times \mathrm{D}+\mathrm{e}_{\mathrm{ij}(\mathrm{k}) \mathrm{m}},
\end{aligned}
$$

where $Y_{\mathrm{ij}(\mathrm{k}) \mathrm{m}}$ was each observation, $\mu$ was the overall mean, $\mathrm{P}_{\mathrm{i}}$ was the fixed effect of parity $\mathrm{i}, \mathrm{T}_{\mathrm{j}}$ was the fixed effect of treatment $\mathrm{j}, \mathrm{C}(\mathrm{T})_{\mathrm{jk}}$ was the random effect of cow $\mathrm{k}$ within treatment $\mathrm{j}, \mathrm{D}_{1}$ was the fixed effect of time (day or week) $1, \mathrm{~T} \times \mathrm{D}$ was the fixed interaction between time and treatment, and $\mathrm{e}_{\mathrm{ij}(\mathrm{k}) \mathrm{m}}$ was the residual. Rumen fermentation data were analyzed with the same mixed-effects model described above but without the effect of time period. The initial values of BW and BCS were considered as covariates. Data were presented as least squares means \pm standard error of the mean. Orthogonal contrasts were used to determine the treatment and parity effects. Contrast statements included (1) CON versus pomegranate by-products (CON vs. PS and PSP); (2) PS versus PSP supplementation (PS vs. PSP); and (3) primiparous versus multiparous. The effects were considered significant when $P \leq 0.05$. A trend was considered to exist if $0.05<P \leq 0.10$.

\section{RESULTS}

\section{Pomegranate By-Products}

Contents of DM, CP, ether extract, NDF, and phenolic compounds were different between pomegranate seeds and peels (Table 2). Pomegranate seed was high in fiber content $(\mathrm{NDF}=49.6 \%)$, intermediate in fat $(12.1 \%)$ and CP (12.6\%), and low in total phenolic and tannin compounds. The concentration of NFC (68.9 vs. $8.3 \%$ ) as well as total phenolic compounds (25.5 vs. 1.6 $\mathrm{g} / \mathrm{kg}$ of DM) and tannin (21.9 vs. $1.3 \mathrm{~g} / \mathrm{kg}$ of DM) was found to be higher in pomegranate peels than pomegranate seeds. Pomegranate peels contained relatively low levels of NDF (19.7\%), CP (3.0\%), and ether extract $(1.9 \%)$. Chemical composition of the 3 diets fed to dairy cows indicated similar energy and protein levels (Table 1). It was found that the inclusion of pomegranate by-products increased the content of total phenolic of experimental diets. The antioxidant activity of PS diets was similar to that of CON diet. However, the antioxidant activity were increased in both pre- and postpartum diets supplemented with pomegranate peels due to the high antioxidant activity of pomegranate peels (91.5\% inhibition of radical activity).

\section{Blood Metabolic Profile and Oxidative Indices}

The mean values and the changes of plasma metabolic status of pre- and postpartum dairy cows are presented in Table 3 and in Figures 1, respectively. We found no effect of dietary pomegranate by-products on preand postpartum plasma concentrations of cholesterol, globulin, total protein, and aspartate aminotransferase (Table 3). Prepartum plasma glucose concentration was the same among the 3 treatments, but postpartum level was lower $(P=0.02$; Table 3$)$ for cows fed pomegranate by-products than cows fed CON. The lowest plasma glucose concentrations were observed in cows fed PSP diet on $\mathrm{d} 1(P=0.07), 7(P=0.004)$, and $21(P=$ 0.002 ) (Figure 1). Pre- and postpartum plasma concentration of TAG was also lower for cows fed pomegranate by-products than for cows fed CON. A lower plasma TAG concentration was observed in cows fed PSP versus cows fed PS at postpartum $(P=0.04)$. Plasma albumin level did not differ significantly be- 
Table 3. Blood metabolites and oxidative status of periparturient dairy cows fed diets containing no pomegranate by-products (CON), pomegranate seed (PS), or pomegranate seed pulp (PSP)

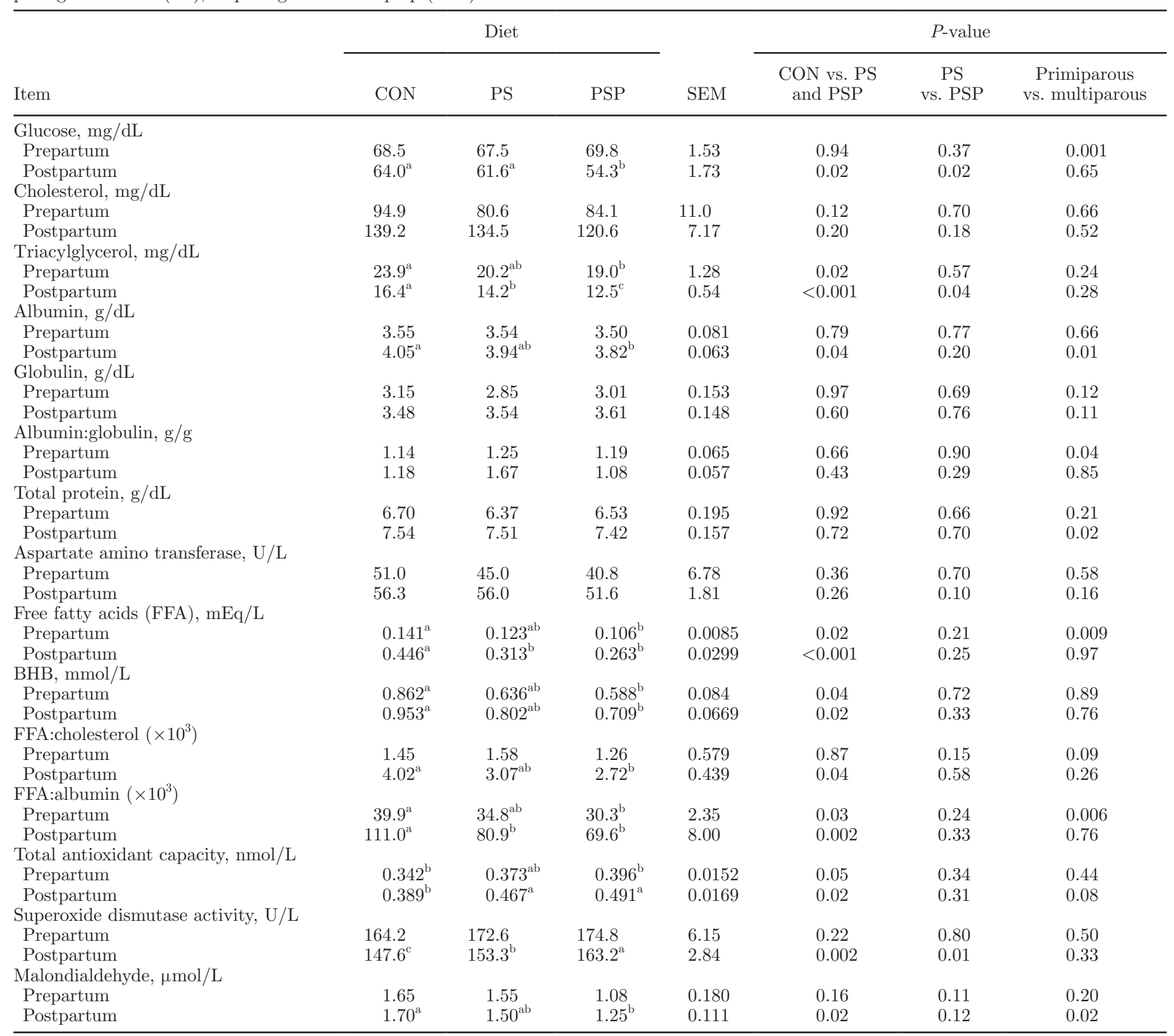

${ }^{\mathrm{a}-\mathrm{c}}$ Means with different superscripts differ $(P<0.05)$.

tween the 3 dietary treatments at prepartum; however, cows supplemented with pomegranate by-products had lower $(P=0.04)$ plasma albumin level than cows fed CON during postpartum.

Results for plasma FFA concentration on d -14 , 1, 7, and 21 relative to calving are shown in Figure 1. Plasma FFA concentrations increased at calving and gradually decreased after calving in cows receiving the PS and PSP diets, but remained almost constant in cows offered the CON diet to d 21 postpartum (Figure 1). Cows fed CON had greater FFA concentration dur- ing prepartum $(P=0.02)$ and postpartum $(P<0.001)$ than cows fed the pomegranate by-products, with the lowest value observed in cows fed PSP (Table 3). This led to greater pre- $(P=0.03)$ and postpartum $(P<$ 0.002) FFA-to-albumin ratio in cows fed CON than cows supplemented the pomegranate by-products despite the greater plasma albumin level in CON group. Moreover, cows on CON diet had a higher $(P=0.04)$ FFA-to-cholesterol ratio than cows on pomegranate by-products diets at postpartum, with no difference between PS and PSP. The highest plasma concentra- 
tion of BHB was observed on d 1 after calving, with the highest value observed in cows on CON diet (Figure 1). The BHB concentration was lower at pre- $(P=0.04)$ and postpartum $(P=0.02$; no treatment effects on $\mathrm{d}$ +7 and +21 , Figure 1 ) in cows fed pomegranate byproducts compared with cows fed CON, without any difference between PSP and PS diets (Table 3).

Plasma total antioxidant capacity was lower at prepartum than postpartum and unchanged up to $\mathrm{d} 1$ postcalving and then increased in all cows (Figure 1). The mean TAC concentration was $0.377,0.442$, and 0.466 $\mathrm{nmol} / \mathrm{L}$ for cows received the CON, PS, and PSP diets, respectively (Table 3 ). Pre- and postpartum plasma levels of TAC were lower in cows received CON than cows supplemented with pomegranate by-products, with no difference between PS and PSP diets. The concentration of plasma MDA showed a trend opposite to that of TAC (Figure 1). The mean plasma concentration of MDA was $1.69,1.50$, and $1.21 \mu \mathrm{mol} / \mathrm{L}$ for cows on CON, PS, and PSP diets, respectively. Cows on the CON diet had greater plasma MDA concentration at postpartum $(P=0.02)$ compared with cows on pomegranate by-products diets (Table 3). Blood SOD was greater at prepartum than postpartum and unchanged up to

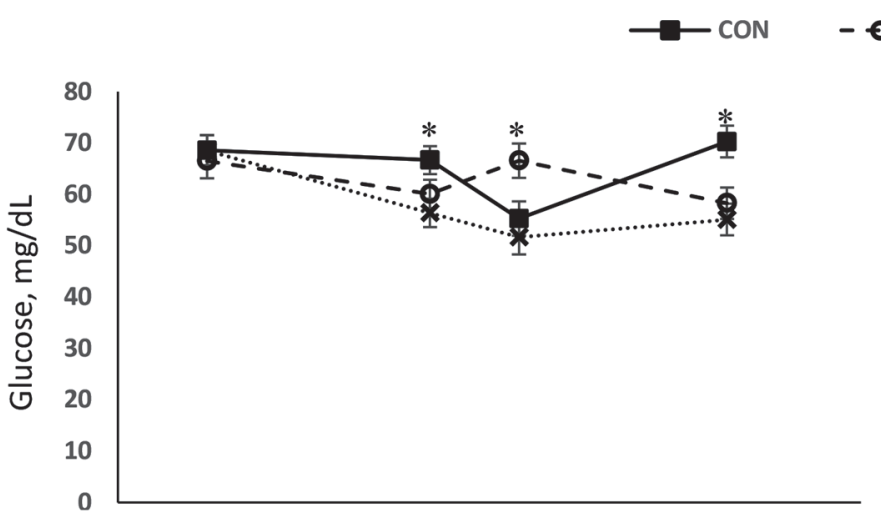

PS $\quad \cdots \times \cdots \cdot$ PSP
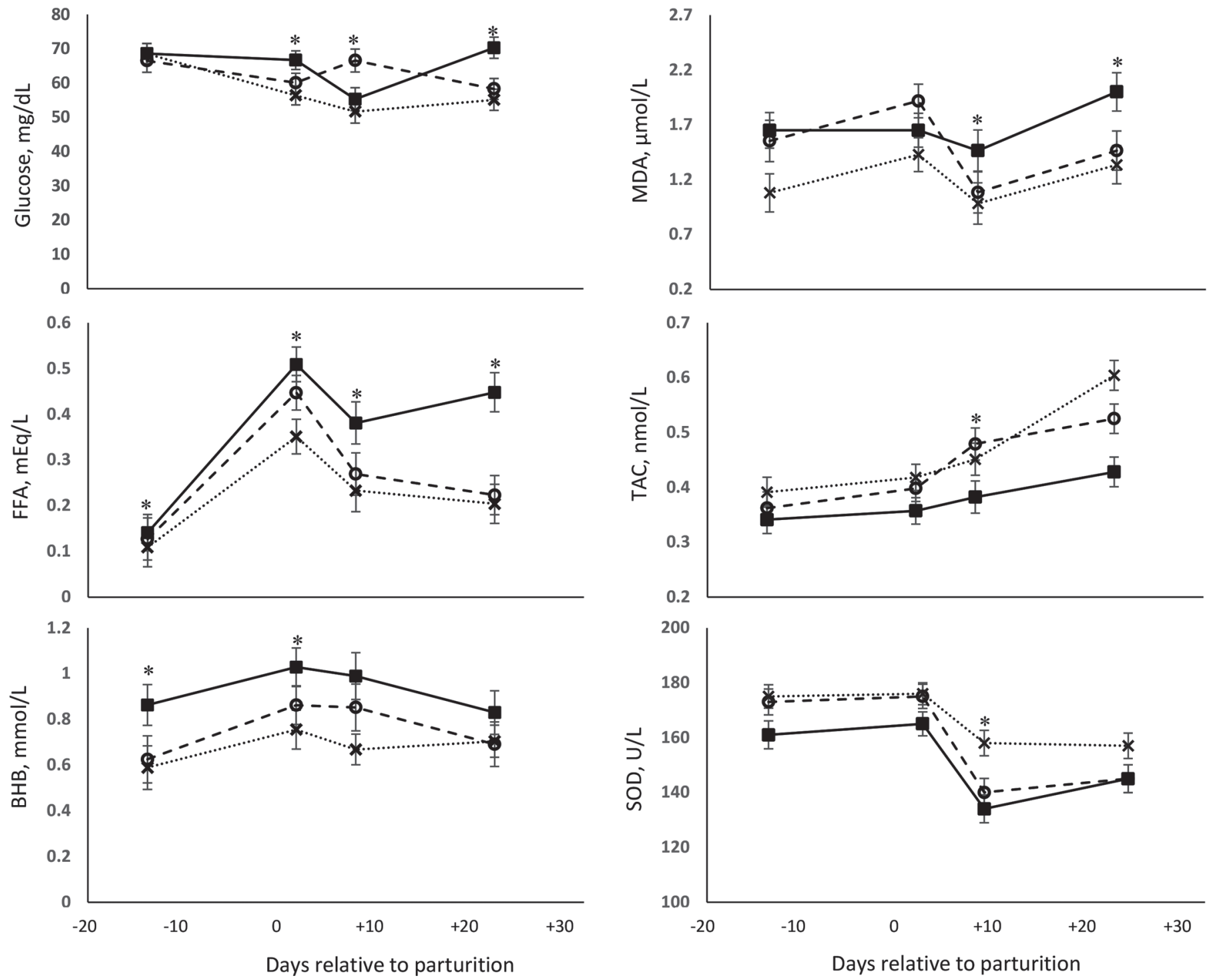

Figure 1. Blood glucose, free fatty acids (FFA), BHB, superoxide dismutase (SOD), total antioxidant activity (TAC), and malondialdehyde (MDA) concentration of periparturient dairy cows fed diets containing no pomegranate by-products (CON), pomegranate seed (PS), or pomegranate seed pulp (PSP). Data were expressed as LSM \pm SEM. ${ }^{*} P<0.05$. 
d 1 postcalving, but thereafter decreased in all cows (Figure 1). The mean SOD activity was 151, 159, and $166 \mathrm{U} / \mathrm{L}$ for the CON, PS, and PSP diets, respectively. Prepartum blood SOD activity was similar among the treatments (Table 3). Nevertheless, cows receiving the CON diet showed lower $(P=0.002)$ blood SOD activity than cows receiving the pomegranate by-products diets, with the highest value observed in cows receiving the PSP $\operatorname{diet}(P=0.01)$. Primiparous cows had higher plasma glucose (prepartum; 72.7 vs. $64.4 \mathrm{mg} / \mathrm{dL}, P=$ 0.001 ) and MDA (postpartum; 1.64 vs. $1.32 \mu \mathrm{mol} / \mathrm{L}, P$ $=0.02$ ) levels, but lower albumin (postpartum; 3.86 vs. $4.01 \mathrm{~g} / \mathrm{dL}, P=0.05$ ), FFA (prepartum; 0.108 vs. 0.139 $\mathrm{mEq} / \mathrm{L} P=0.009$ ), FFA-to-albumin ratio (prepartum; $P=0.006$ ), and TAC (postpartum; 0.432 vs. 0.467 nmol/L, $P=0.08$ ) than multiparous cows (Table 3 ).

\section{DMI, Milk Production, and Ruminal Fermentation}

Dry matter intake, BW, BCS, milk yield, and milk composition of transition cows fed diets supplemented with pomegranate by-products are reported in Table 4. Prepartum DMI was $15.7,15.4$, and $16.8 \mathrm{~kg} / \mathrm{d}$ and postpartum DMI was $16.7,16.4$, and $18.0 \mathrm{~kg} / \mathrm{d}$ for cows fed CON, PS, and PSP diets, respectively. No differences were observed in pre- and postpartum DMI between $\mathrm{CON}$ and pomegranate by-products supplemented groups and between PS and PSP groups $(P>0.05)$. The actual DMI values were greater than the predicted DMI (12 and $16 \mathrm{~kg} / \mathrm{d}$ for pre- and postpartum, respectively), which lead to slightly greater intake of pomegranate seed (0.4 vs. $0.35 \mathrm{~kg} / \mathrm{d})$ and pomegranate seed pulp (1.7 vs. $1.35 \mathrm{~kg} / \mathrm{d}$ ) than those predicted before the experiment. Initial BW and BCS were similar across dietary treatment. However, BW change $(\mathrm{kg} / \mathrm{d}$, from $\mathrm{d}-25$ to 25 relative to calving) was significantly higher $(P=$ $0.05)$ and BCS change tended to be greater $(P=0.08)$ in $\mathrm{CON}$ versus pomegranate-supplemented groups. No effect of pomegranate by-products supplementation on milk yield and composition were found across the dietary treatments. However, a trend $(P=0.09)$ for increased $3.5 \%$ FCM was observed when pomegranate by-products were supplemented in the diet. Yields of $3.5 \%$ FCM $(P=0.02)$, ECM $(P=0.02)$, milk fat $(P=$ $0.01)$, TS $(P=0.02)$, protein $(P=0.07)$, and lactose $(P=0.09)$ were higher for cows fed the PSP diet than cows fed the PS diet, with no difference between CON and PS. As cows fed the PSP diet consumed numerically more DM and produced more milk, milk efficiency (milk yield/DMI) was similar across dietary treatments. Furthermore, cows fed diets containing pomegranate by-products during $180 \mathrm{~d}$ postpartum (1 record per month) tended to have a greater milk yield $(P=0.08)$ compared with those fed the CON diet. Initial BCS was the same between primiparous and multiparous cows, but multiparous cows had greater DMI (18.7 vs. 15.4 $\mathrm{kg} / \mathrm{d}, P=0.02)$, milk production (44.7 vs. $32.8 \mathrm{~kg} / \mathrm{d}, P$ $<0.001$ ), and milk efficiency (2.43 vs. $2.15, P=0.05$ ) and tended to have higher milk fat content (3.45 vs. $3.07 \%, P=0.06)$, as well as BW change $(P=0.15)$, than primiparous cows.

Ruminal pH did not differ between CON and pomegranate by-product-supplement groups or between PS and PSP (Table 5). Moreover, supplementation of pomegranate by-products in the diets did not affect total SCFA concentrations, the molar proportions of propionate, butyrate, valerate, isovalerate, or the acetate-to-propionate ratio.

\section{DISCUSSION}

\section{Pomegranate By-Products}

Iran is one of the world's largest producers and exporters of pomegranate fruit, with approximately 1 million tonnes of production in 2014 (Ministry of Agriculture, 2015). As a result of pomegranate juice production, a great quantity of pomegranate by-products (over $50 \%$ ), mainly seeds and peels that contain high levels of moisture ( $\sim 20 \% \mathrm{DM})$, are generated. The storage of these by-products require additional processing methods, such as ensiling, drying, or extracting their bioactive compounds before feeding. In our study, sundried pomegranate peels had $25.5 \mathrm{~g} / \mathrm{kg}$ of DM phenolic compounds, similar to the phenolic content of pomegranate silage $(22.5 \mathrm{~g} / \mathrm{kg}$ of DM; Kotsampasi et al., 2014). The pomegranate seed used in the current study contained $12.1 \%$ fat. The oil content in pomegranates seed of 25 varieties grown in Iran ranged from 6.6 to $19.3 \%$ with punicic acid as the predominant FA (31.8 to $86.6 \%$; Fadavi et al., 2006). We hypothesized that the supplementation of pomegranate seed or combined pomegranate seed and peels with rich bioactive compounds, such as conjugated FA and phenolics, might improve antioxidant statue, thereby exerting positive influences on health and performance of dairy cows during transition period. In the present study, inclusion of pomegranate by-products into pre- and postpartum TMR, in particular PSP, increased dietary total phenolic contents ( $>2$ times) and antioxidant activity $(81.9 \%)$.

\section{Oxidative and Metabolic Status}

Under normal cellular metabolism, a balance exists between the levels of ROS and levels of endogenous antioxidants (Pham-Huy et al., 2008). However, the overproduction of ROS (e.g., during transition period 
Table 4. Dry matter intake, BW, BCS, milk yield, milk composition, and feed efficiency of periparturient dairy cows fed diets containing no pomegranate by-products (CON), pomegranate seed (PS), or pomegranate seed pulp (PSP)

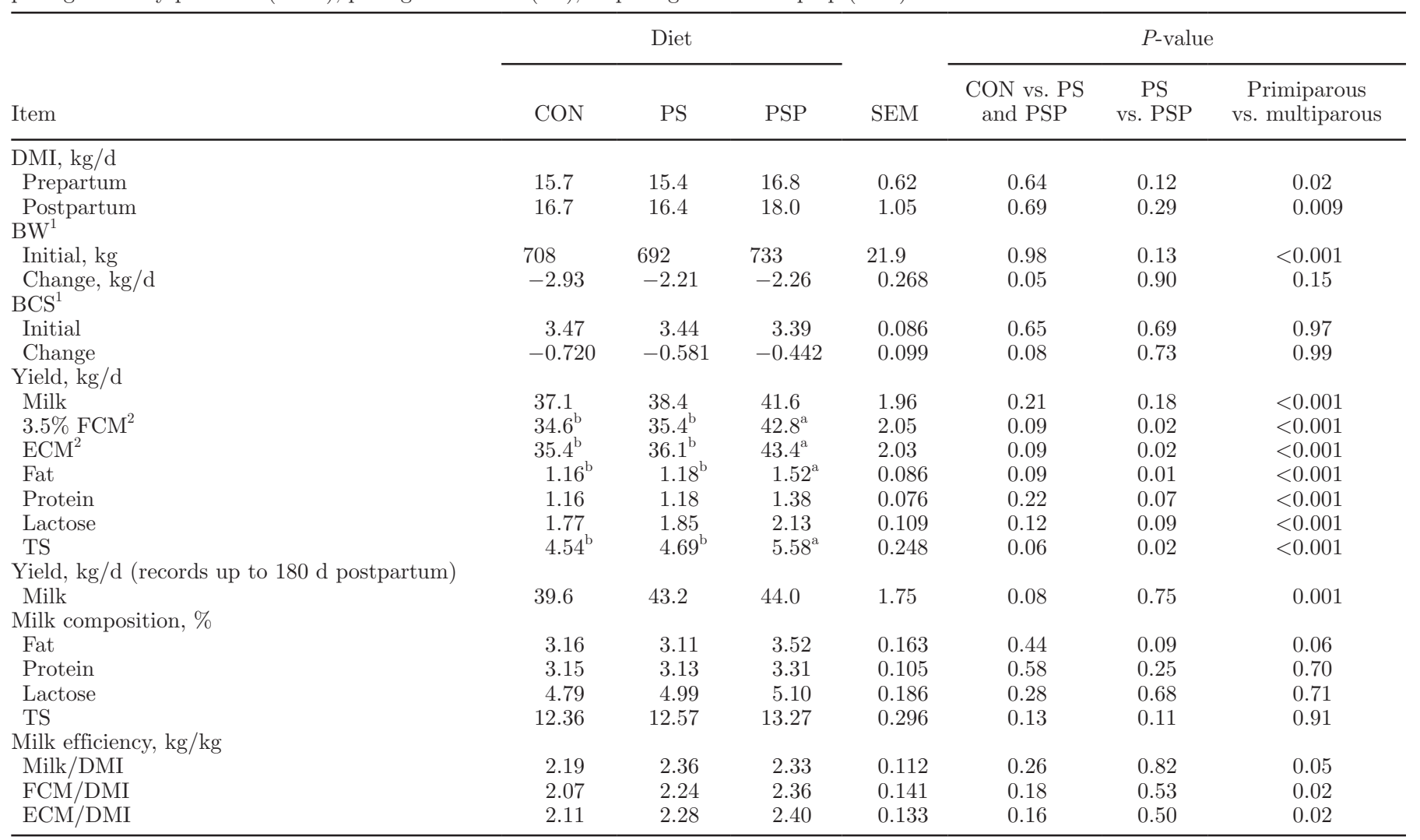

$\overline{\mathrm{a}, \mathrm{b}}$ Means within a row with different superscripts differ $(P<0.05)$.

${ }^{1}$ Body weight and BCS changes during the transition period ( $d-25$ to +25 relative to parturition).

${ }^{2}$ Yields of $3.5 \% \mathrm{FCM}=0.432 \times$ milk yield $+16.23 \times$ fat yield and $\mathrm{ECM}=12.82 \times$ fat yield $+7.13 \times$ protein yield $+0.323 \times$ milk yield according to NRC (2001) equations.

due to augmented metabolic demands) overwhelms the neutralizing capacity of antioxidant mechanisms, and this might results in high lipid peroxidation and decreased level of antioxidant enzymes (Bernabucci et al., 2005; Bertoni et al., 2006; Pham-Huy et al., 2008). A recent study has provided increasing evidence that oxidative stress has been associated with several health problems, especially during transition period (Abuelo et al., 2016). Our results demonstrated that supplementation with either PS or PSP had positive effects on antioxidant status, as indicated by enhanced blood TAC and SOD activity and depressed MDA level. Similar to

Table 5. Rumen fermentation of periparturient dairy cows fed diets containing no pomegranate by-products (CON), pomegranate seed (PS), or pomegranate seed pulp (PSP)

\begin{tabular}{|c|c|c|c|c|c|c|c|}
\hline \multirow[b]{2}{*}{ Item } & \multicolumn{3}{|c|}{ Diet } & \multirow[b]{2}{*}{ SEM } & \multicolumn{3}{|c|}{$P$-value } \\
\hline & $\mathrm{CON}$ & PS & PSP & & $\begin{array}{l}\text { CON vs. PS } \\
\text { and PSP }\end{array}$ & $\begin{array}{c}\text { PS } \\
\text { vs. PSP }\end{array}$ & $\begin{array}{c}\text { Primiparous } \\
\text { vs. multiparous }\end{array}$ \\
\hline$\overline{\mathrm{pH}}$ & 6.19 & 6.17 & 6.27 & 0.152 & 0.86 & 0.65 & 0.79 \\
\hline $\mathrm{SCFA},{ }^{1} \mathrm{~m} M$ & 72.5 & 77.3 & 82.9 & 5.78 & 0.32 & 0.57 & 0.25 \\
\hline Acetate, \% & 65.8 & 66.3 & 64.0 & 2.76 & 0.83 & 0.55 & 0.63 \\
\hline Propionate, \% & 23.2 & 23.3 & 24.4 & 1.84 & 0.78 & 0.67 & 0.83 \\
\hline Butyrate, \% & 9.02 & 8.74 & 10.94 & 1.43 & 0.65 & 0.31 & 0.21 \\
\hline Valerate, \% & 1.72 & 1.52 & 1.52 & 0.107 & 0.12 & 0.99 & 0.02 \\
\hline Isovalerate, \% & 0.125 & 0.098 & 0.108 & 0.011 & 0.11 & 0.50 & 0.25 \\
\hline Acetate:propionate & 3.08 & 2.98 & 2.79 & 0.385 & 0.68 & 0.72 & 0.77 \\
\hline
\end{tabular}

${ }^{1}$ Short-chain fatty acids. 
these findings, herbal supplementation with rich polyphenol contents increased blood TAC and decreased MDA levels during the transition period (Hashemzadeh-Cigari et al., 2015). Previous studies also indicated that total phenolic contents and antioxidant activity in meat (Kotsampasi et al., 2014) and milk (Shabtay et al., 2012) were improved significantly when animals were fed diets containing pomegranate-derived supplements. Phenolic substances can prevent lipid peroxidation by scavenging free radicals or by activation of antioxidant enzymes such as glutathione reductase, glutathione peroxidase, and SOD (Tzulker et al., 2007; Wang et al., 2010). Moreover, conjugated FA, such as CLA or those found in PS (i.e., punicic acid) have been shown to be effective supplements in terms of lipid peroxidation by inhibition of prostaglandins biosynthesis (Singh et al., 2002; Hanschke et al., 2016). The results of our study indicated a larger improvement in antioxidant status and lipid peroxidation inhibitory in cows supplemented with both pomegranate seed and peel (PSP) compared with those supplemented with pomegranate seed alone. In accord, previous studies (Singh et al., 2002; Tzulker et al., 2007) demonstrated higher antioxidant activity $(54 \%)$ of pomegranate peel than seed, which can be related to the high radical-scavenging activities of phenolic contents such as punicalagin or punicalin in pomegranate peel.

High plasma concentrations of $\mathrm{BHB}$ at prepartum $(0.86 \mathrm{mM})$ and postpartum (d $1=1.03 \mathrm{mM}$ and $\mathrm{d} 7$ $=0.99 \mathrm{~m} M$ ) were observed when cows were fed the CON diet. It has been suggested that prevalence rates of postpartum disorders (e.g., displaced abomasum) is higher when plasma BHB concentrations are above 0.6 to $0.8 \mathrm{~m} M$ at prepartum and 1.0 to $1.4 \mathrm{~m} M$ at postpartum (Ospina et al., 2013). Plasma BHB concentrations decreased when cows were fed diets supplemented with either PS (26\% prepartum and $16 \%$ postpartum) or PSP (31\% prepartum and $26 \%$ postpartum). Around calving, mobilization of FA from TAG stores in adipose tissue are favored due to increasing energy requirement and decreasing DMI (Contreras and Sordillo, 2011). In the liver, FFA can be completely oxidized to $\mathrm{CO}_{2}$ to provide energy, partially oxidized to generate ketone bodies, or esterified to TAG and exported from the liver. An alternative pathway for liver FFA oxidation is an increase in the peroxisomal oxidation capacity, which contributes to the production of ROS and affects inflammatory responses (Sordillo and Raphael, 2013). In the current study, the reduction of BHB level was parallel with the decrease of FFA (33\%) and MDA (20\%) concentration by feeding diets containing either PS or PSP. Our results agree with other studies that reported a lower FFA concentration in dairy sheep (Chiofalo et al., 2012) and cattle (Hashemzadeh-Cigari et al., 2015) supplemented with medicinal plant extracts. Bernabucci et al. (2005) demonstrated increased oxidative stress in cows with greater BCS loss concurrent with higher FFA and BHB concentrations postpartum. In our study, initial cow BW and BCS were similar among treatment groups, but cows fed the CON diet had greater BW (25\%) and BCS (28\%) loss than cows supplemented with pomegranate by-products. Whereas FFA are a major fuel source during periods of energy shortage, high concentrations of FFA are known to disrupt several inflammatory and immune functions (Sordillo and Raphael, 2013). Dietary supplementation with antioxidants can protect against the damaging influence of oxidants and downregulate mRNA expression of proinflammatory cytokines, which adversely affect lipolysis rate in transition cows (Bertoni et al., 2008; Sordillo and Raphael, 2013). Polyphenol compounds, such as hydrolysable tannins, anthocyanins, and ellagic acid, have been shown to correlate positively with antioxidant and anti-inflammatory activities in pomegranate peel and juice (Tzulker et al., 2007; Jurenka, 2008). Furthermore, it was previously shown that pomegranate seed oil possess antioxidant and anti-inflammatory activity by inhibiting cyclooxygenases and lipoxygenases (Singh et al., 2002).

Dietary supplementation with pomegranate by-products resulted in a significant decrease of postpartum blood glucose levels and the lowest values (d 1, 7, and $25)$ were observed when cows were fed the diet containing PSP. As dietary pomegranate by-product supplementation had no effect on DMI and ruminal fermentation pattern (i.e., propionate), lower blood glucose may be related to greater FCM yield, antioxidant status, or degree of insulin sensitivity. This would likely suggest an enhancement in insulin sensitivity in cows fed the PSP diet, which consequently increased glucose utilization and decreased fat mobilization and plasma nonesterified FA and BHB levels. It has been reported that quercetin (Gohlke et al., 2013) or herbal plant mixture (Hashemzadeh-Cigari et al., 2015) supplementation in cows resulted in changes in glucose metabolism, indicating increased insulin release or sensitivity; those authors suggested that the response might be responsible for improved performance response. Experimental evidence supports the idea ROS are an important trigger for insulin resistance, and reduced glucose consumption capacity and antioxidant supplementation can be used to decrease the consequences of insulin resistance (Houstis et al., 2006; Abuelo et al., 2016).

We found no effects of pomegranate by-products supplementation on plasma cholesterol, FFA-to-cholesterol ratio, total protein, globulin, and AST concentrations, and the values were within the ranges of normally fed cows. Supplementation with pomegranate by-products 
lowered plasma TAG concentration in both the preand postpartum periods. In transition cows, adipose tissues are mobilized and FFA are transported to the liver where they are either oxidized or re-esterified to TAG and then are packed in very low density lipoproteins to export from the liver (Bertoni et al., 2006). Because plasma cholesterol concentration were well above the critical value $(\sim 2 \mathrm{~m} M$ or $77 \mathrm{mg} / \mathrm{dL}$; Bertoni et al., 2008), the lower plasma TAG in supplemented cows may be related to lowered body fat mobilization (lower BW loss) or enhanced clearance from plasma lipoproteins. Sahin et al. (2006) observed that supplementation of antioxidants decreased elevated levels of plasma cholesterol and TAG under stress exposure. Albumin is a negative acute phase protein in plasma and contains domains to bind hydrophobic compounds, including FFA. Although albumin concentration was the lowest in cows fed diets containing pomegranate by-products, all the cows had albumin concentrations well above the critical value $(3.0 \mathrm{~g} / \mathrm{dL})$ based on liver activity index (Bertoni et al., 2008). The ratio of FFA to albumin, which is as an index for predicting postpartum disease incidence (Contreras and Sordillo, 2011), was greater in cows fed CON than those fed pomegranate by-products, indicating cows supplemented with PSP and PS possibly had a slight improvement in liver function than unsupplemented cows. In humans, elevated FFA-to-albumin ratios are part of pathological changes of metabolic diseases such as type 2 diabetes (Cnop et al., 2001).

\section{Intake and Lactation Performance}

Dietary supplementation with PS or PSP had no effect on pre- and postpartum DMI, ruminal pH, SCFA concentrations, and molar proportions of individual SCFA. Inclusion of pomegranate extracts in the diet of dairy cows has been shown to improve DMI and rumen pH in some (Jami et al., 2012), but not all (Abarghuei et al., 2013; Shaani et al., 2016), studies. These differences may be due to different type and level of pomegranate supplements (pomegranate residues or extract), as well as different animal conditions. Pomegranate peel is rich in tannin compounds, which have been shown to have both adverse and beneficial effects, such as reducing ruminal protein degradation, DMI, and $\mathrm{CH}_{4}$ production and increasing concentration of propionic acid. Moderate levels of tannin-containing feed supplementation improved nitrogen balance, milk production of ruminants without negatively affecting DMI (Hymes-Fecht et al., 2013). Jami et al. (2012) found that supplementing with $4 \%$ pomegranate peel extract to lactating cows improved ruminal $\mathrm{pH}$, DMI, and nutrient digestibility. Our findings show that feeding PSP at level of 8 to $10 \%$ in transition dairy cows (providing $50 \mathrm{~g} / \mathrm{d}$ of tannin in the diet DM) was not excessive to reduce palatability or rumen microorganism activities, thereby decreasing SCFA production and DMI.

The supplementation of pomegranate by-products had no effect on milk yield and milk efficiency; however, supplementing diet containing PSP significantly increased FCM, ECM, and milk composition yields. Different effects of adding pomegranate-derived products on performance responses have been reported for growing cattle and lactating dairy cows (Shabtay et al., 2008, 2012; Jami et al., 2012; Abarghuei et al., 2013; Shaani et al., 2016). Although DMI was not affected by treatments in our experiment, the improvement in metabolic and antioxidative status in cows fed the PSP diet may be responsible in part for higher milk production performance. Shabtay et al. (2012) reported that mid-lactation cows with high SCC fed $4 \%$ concentrated pomegranate extract were more resistant to mastitis and produced $9.4 \%$ more milk than their control counterparts. Metabolic disorders are a key problem in the transition period of dairy cows and results in milk lost during the entire lactation. Wang et al. (2010) observed an improved antioxidative status and a tendency for increased FCM yield when a synthetic antioxidant was included during transition period.

We showed that blood level of MDA during postpartum was significantly greater and that of TAC and albumin was lower in primiparous cows compared with multiparous cows. However, primiparous cows produced less milk and showed a lower level of FFA than multiparous cows. These findings suggest that primiparous cows had more oxidative stress but less metabolic load around parturition. Ospina et al. (2010) indicated that milk yield was increased in primiparous cows and decreased in multiparous cows when FFA and BHB concentrations were greater than the critical values. A recent study by Omidi et al. (2017) demonstrated that primiparous cows were more sensitive to oxidative stress as a result of lower TAC than multiparous cows, and supplemental dietary antioxidants (vitamin $\mathrm{E}$ and zinc) reduced oxidative stress and severity of udder edema in primiparous cows (NRC, 2001). New physiological experience (giving birth for the first time) and feeding management strategies (e.g., unexperienced high-grain diets) could be possible reasons for more susceptibility of primiparous cows (NRC, 2001; Humer et al., 2018).

\section{CONCLUSIONS}

Feeding pomegranate by-products during transition periods (8-10\% diet DM) had no effect on DMI, but enhanced overall antioxidant capacity and declined lipid peroxidation (MDA). These beneficial effects were 
associated with decreases in BW loss, FA mobilization, and oxidation (lowered FFA and BHB concentrations). However, larger improvements in antioxidant status and metabolic profile, as well as ECM production following PSP supplementation, were observed, possibly due to the feeding combined bioactive compounds (phenolics and conjugated FA) and a high antioxidant level of pomegranate peel.

\section{ACKNOWLEDGMENTS}

Authors express appreciation to the Lavark Research Station dairy farm staff (Isfahan University of Technology, Isfahan, Iran) and Javad Shirani (Isfahan University of Technology) for their help, and the animal nutrition laboratory staff for the technical assistance at the Isfahan University of Technology. Amir Mansour Vatankhah (Clinical Biochemistry, Drug Applied Research Center, Tabriz University of Medical Sciences, Tabriz, Iran) is acknowledged for analyzing blood parameters. Isfahan University of Technology supported this study.

\section{REFERENCES}

Abarghuei, M. J., Y. Rouzbehan, A. Z. M. Salem, and M. J. Zamiri. 2013. Nutrient digestion, ruminal fermentation and performance of dairy cows fed pomegranate peel extract. Livest. Sci. 157:452-461.

Abuelo, A., J. Hernandez, J. L. Benedito, and C. Castillo. 2016. Association of oxidative status and insulin sensitivity in periparturient dairy cattle: An observational study. J. Anim. Physiol. Anim. Nutr. (Berl.) 100:279-286.

AOAC International. 2000. Official Methods of Analysis. 17th ed. AOAC International, Arlington, VA.

Aviram, M., L. Dornfeild, M. Rosenblat, N. Volkova, M. Kaplan, R. Coleman, T. Hayek, D. Presser, and B. Fuhrman. 2000. Pomegranate juice consumption reduces oxidative stress, atherogenic modifications to LDL, and platelet aggregation: Studies in humans and in atherosclerotic apolipoprotein E-deficient mice. Am. J. Clin. Nutr. 71:1062-1076.

Bamdad, F., M. Kadivar, and J. Keramat. 2006. Evaluation of phenolic content and antioxidant activity of Iranian caraway in comparison with clove and BHT using model systems and vegetable oil. Int. J. Food Sci. Technol. 41:20-27.

Bernabucci, U., B. Ronchi, N. Lacetera, and A. Nardone. 2005. Influence of body condition score on relationships between metabolic status and oxidative stress in periparturient dairy cows. J. Dairy Sci. 88:2017-2026.

Bertoni, G., E. Trevisi, L. Calamari, and M. Bionaz. 2006. The inflammation could have a role in the liver lipidosis occurrence in dairy cows. Pages 157-158 in Production Diseases in Farm Animals, 12th Int. Conf. N. Joshi and T. H. Herdt, ed. Wageningen Academic Publ., Wageningen, the Netherlands.

Bertoni, G., E. Trevisi, X. Han, and M. Bionaz. 2008. Effects of inflammatory conditions on liver activity in puerperium period and consequences for performance in dairy cows. J. Dairy Sci. 91:33003310.

Brzezinska-Slebodzinska, E., J. K. Miller, J. D. Quigley, J. R. Moore, and F. C. Madsen. 1994. Antioxidant status of dairy cows supplemented prepartum with vitamin E and selenium. J. Dairy Sci. 77:3087-3095

Chiofalo, V., L. Liotta, R. Fiumanò, E. B. Riolo, and B. Chiofalo. 2012. Influence of dietary supplementation of Rosmarinus officina- lis L. on performances of dairy ewes organically managed. Small Rumin. Res. 104:122-128.

Cnop, M., J. C. Hannaert, A. Hoorens, D. C. L. Eizirik, and D. G. Pipeleers. 2001. Inverse relationship between cytotoxicity of free fatty acids in pancreatic islet cells and cellular triglyceride accumulation. Diabetes 50:1771-1777.

Contreras, G. A., and L. M. Sordillo. 2011. Lipid mobilization and inflammatory responses during the transition period of dairy cows. Comp. Immunol. Microbiol. Infect. Dis. 34:281-289.

Fadavi, A., M. Barzegar, and M. H. Azizi. 2006. Determination of fatty acids and total lipid content in oilseed of 25 pomegranates varieties grown in Iran. J. Food Compos. Anal. 19:676-680.

Gaál, T., P. Ribiczeyne-Szabo, K. Stadler, J. Jakus, J. Reczigel, P. Kover, M. Mezes, and L. Sumeghly. 2006. Free radicals, lipid peroxidation and the antioxidant system in the blood of cows and newborn calves around calving. Comp. Biochem. Physiol. B Biochem. Mol. Biol. 143:391-396.

Gohlke, A., C. J. Ingelmann, G. Nürnberg, J. M. Weitzel, H. M. Hammon, S. Görs, A. Starke, S. Wolffram, and C. C. Metges. 2013. Influence of 4-week intraduodenal supplementation of quercetin on performance, glucose metabolism, and mRNA abundance of genes related to glucose metabolism and antioxidative status in dairy cows. J. Dairy Sci. 96:6986-7000.

Hanschke, N., M. Kankofer, L. Ruda, M. Höltershinken, U. Meyer, J. Frank, S. Dänicke, and J. Rehage. 2016. The effect of conjugated linoleic acid supplements on oxidative and antioxidative status of dairy cows. J. Dairy Sci. 99:8090-8102.

Hashemzadeh-Cigari, F., G. R. Ghorbani, M. Khorvash, A. Riasi, A. Taghizadeh, and Q. Zebeli. 2015. Supplementation of herbal plants differently modulated metabolic profile, insulin sensitivity, and oxidative stress in transition dairy cows fed various extruded oil seeds. Prev. Vet. Med. 118:45-55.

Houstis, N., E. D. Rosen, and E. S. Lander. 2006. Reactive oxygen species have a causal role in multiple forms of insulin resistance. Nature 440:944-948.

Humer, E., R. M. Petri, J. R. Aschenbach, B. J. Bradford, G. B. Penner, M. Tafaj, K. H. Südekum, and Q. Zebeli. 2018. Invited review: Practical feeding management recommendations to mitigate the risk of subacute ruminal acidosis in dairy cattle. J. Dairy Sci. 101:872-888.

Hymes-Fecht, U. C., G. A. Broderick, R. E. Muck, and J. H. Grabber. 2013. Replacing alfalfa or red clover silage with birdsfoot trefoil silage in total mixed rations increases production of lactating dairy cows. J. Dairy Sci. 96:460-469.

Jami, E., A. Shabtay, M. Nikbachat, E. Yosef, J. Miron, and I. Mizrahi. 2012. Effects of adding a concentrated pomegranate-residue extract to the ration of lactating cows on in vivo digestibility and profile of rumen bacterial population. J. Dairy Sci. 95:5996-6005.

Jurenka, J. S. 2008. Therapeutic applications of pomegranate (Punica granatum L.): A review. Altern. Med. Rev. 13:128.

Kotsampasi, B., V. Christodoulou, A. Zotos, M. Liakopoulou-Kyriakides, P. Goulas, K. Petrotos, P. Natas, and V. Bampidis. 2014. Effects of dietary pomegranate byproduct silage supplementation on performance, carcass characteristics and meat quality of growing lambs. Anim. Feed Sci. Technol. 197:92-102.

Liu, G., X. Xu, Q. Hao, and Y. Gao. 2009. Supercritical CO2 extraction optimization of pomegranate (Punica granatum L.) seed oil using response surface methodology. Lebensm. Wiss. Technol. 42:1491-1495.

Ministry of Agriculture. 2015. Iran Agriculture Statistics, 1394. Horticulture Products, Ministry of Agriculture. Accessed Mar. 17, 2015. http://www.maj.ir/dorsapax/userfiles/file/bagh-94.pdf.

Modaresi, J., M. F. Nasri, L. Rashidi, O. Dayani, and E. Kebreab. 2011. Short communication: Effects of supplementation with pomegranate seed pulp on concentrations of conjugated linoleic acid and punicic acid in goat milk. J. Dairy Sci. 94:4075-4080.

NRC. 2001. Nutrient Requirements of Dairy Cattle. 7th rev. ed. Natl. Acad. Sci., Washington, DC.

Omidi, A., M. H. Fathi, and M. O. Parker. 2017. Alterations of antioxidant status markers in dairy cows during lactation and in the dry period. J. Dairy Res. 84:49-53. 
Ospina, P. A., J. A. McArt, T. R. Overton, T. Stokol, and D. V. Nydam. 2013. Using nonesterified fatty acids and $\beta$-hydroxybutyrate concentrations during the transition period for herd-level monitoring of increased risk of disease and decreased reproductive and milking performance. Vet. Clin. North Am. Food Anim. Pract. 29:387-412.

Ospina, P. A., D. V. Nydam, T. Stokol, and T. R. Overton. 2010. Associations of elevated nonesterified fatty acids and $\beta$-hydroxybutyrate concentrations with early lactation reproductive performance and milk production in transition dairy cattle in the northeastern United States. J. Dairy Sci. 93:1596-1603.

Pham-Huy, L. A., H. He, and C. Pham-Huy. 2008. Free radicals, antioxidants in disease and health. Int. J. Biomed. Sci. 4:89-96.

Sahin, N., K. Sahin, M. Onderci, M. Karatepe, M. O. Smith, and O. Kucuk. 2006. Effects of dietary lycopene and vitamin E on egg production, antioxidant status and cholesterol levels in Japanese quail. Asian-Australas. J. Anim. Sci. 19:224-230.

Shaani, Y., D. Eliyahu, I. Mizrahi, E. Yosef, Y. Ben-Meir, M. Nikbachat, R. Solomon, S. J. Mabjeesh, and J. Miron. 2016. Effect of feeding ensiled mixture of pomegranate pulp and drier feeds on digestibility and milk performance in dairy cows. J. Dairy Res. 83:35-41.

Shabtay, A., H. Eitam, Y. Tadmor, A. Orlov, A. Meir, P. Weinberg, Z. G. Weinberg, Y. Chen, A. Brosh, I. Izhaki, and Z. Kerem. 2008. Nutritive and antioxidative potential of fresh and stored pomegranate industrial byproduct as a novel beef cattle feed. J. Agric. Food Chem. 56:10063-10070.

Shabtay, A., M. Nikbachat, A. Zenou, E. Yosef, O. Arkin, O. Sneer, A. Shwimmer, A. Yaari, E. Budmand, G. Agmond, and J. Miron.
2012. Effects of adding a concentrated pomegranate extract to the ration of lactating cows on performance and udder health parameters. Anim. Feed Sci. Technol. 175:24-32.

Singh, R. P., K. N. C. Murthy, and G. K. Jayaprakasha. 2002. Studies on the antioxidant activity of pomegranate (Punica granatum) peel and seed extracts using in vitro models. J. Agric. Food Chem. 50:81-86.

Sordillo, L. M., and W. Raphael. 2013. Significance of metabolic stress, lipid mobilization, and inflammation on transition cow disorders. Vet. Clin. North Am. Food Anim. Pract. 29:267-278.

Tzulker, R.. I. Glazer, I. Bar-Ilan, D. Holland, M. Aviram, and R. Amir. 2007. Antioxidant activity, polyphenol content, and related compounds in different fruit juices and homogenates prepared from 29 different pomegranate accessions. J. Agric. Food Chem. 55:9559-9570.

Wang, Y. M., J. H. Wang, C. Wang, J. K. Wang, B. Chen, J. X. Liu, H. Cao, and F. C. Guo. 2010. Effect of dietary antioxidant and energy density on performance and anti-oxidative status of transition cows. Asian-Australas. J. Anim. Sci. 23:1299-1307.

Yasui, T., C. M. Ryan, R. O. Gilbert, K. R. Perryman, and T. R. Overton. 2014. Effects of hydroxy trace minerals on oxidative metabolism, cytological endometritis, and performance of transition dairy cows. J. Dairy Sci. 97:3728-3738.

Zhang, X. Y., Y. L. Tan, L. Y. Cao, G. Y. Wu, Q. Xu, Y. Shen, and D. F. Zhou. 2006. Antioxidant enzymes and lipid peroxidation in different forms of schizophrenia treated with typical and atypical antipsychotics. Schizophr. Res. 81:291-300. 